\title{
The effective evaluation of thyroid status in patients on phenytoin, carbamazepine or sodium valproate attending an epilepsy clinic
}

\author{
A.A. Connacher, D.Q. Borsey, M.C.K. Browning, ${ }^{1}$ D.L.W. Davidson ${ }^{2}$ and R.T. \\ Jung
}

University Departments of Medicine, ${ }^{1}$ Biochemical Medicine and ${ }^{2}$ Neurology, Ninewells Hospital and Medical School, Dundee DD1 9SY, Scotland, UK.

\begin{abstract}
Summary: To assess the most efficient means of monitoring thyroid status in an epilepsy clinic, total thyroxine $\left(\mathrm{T}_{4}\right)$, free thyroxine $\left(\mathrm{FT}_{4}\right)$ and thyroid stimulating hormone (TSH) were measured in 71 adult patients treated long-term with either phenytoin (DPH), carbamazepine (CBZ) or sodium valproate (VAL). Twenty-seven patients with one or more abnormal thyroid hormone results were further investigated by a thyrotrophin releasing hormone (TRH) test and clinical assessment. $T_{4}$ was found to be normal in $85 \%$ on VAL, $40 \%$ on CBZ and $39 \%$ on DPH. FT 4 was normal in more patients, namely $95 \%$ on VAL, 70\% on CBZ and 65\% on DPH. The TRH tests indicated that FT ${ }_{4}$ was the most efficient screening test for hypothyroidism in this epileptic population. We estimate that the use of $\mathrm{FT}_{4}$ alone as a screening test would have reduced by $60 \%$ the number of TRH tests required.
\end{abstract}

\section{Introduction}

Long-term administration of anticonvulsant drugs is well known to affect blood thyroid hormone levels.' Despite a reduction in serum total thyroxine $\left(\mathrm{T}_{4}\right)$ and free thyroxine $\left(\mathrm{FT}_{4}\right)$ most studies have emphasized that patients receiving anticonvulsants appear clinically euthyroid with normal reference levels of thyroid stimulating hormone (TSH). Nevertheless, there does seem to be a small number of patients in whom abnormalities in TSH levels do occur ${ }^{2-4}$ and cases of reversible hypothyroidism induced by phenytoin [diphenyl-hydantoin (DPH)] and carbamazepine (CBZ) have also been reported. ${ }^{5}$ In such patients symptoms due to the side effects of their medication may be difficult to distinguish from those due to hypothyroidism. This, therefore, means that long term monitoring of thyroid function in patients on anticonvulsants is necessary. Our objective was to study patients treated long-term with either DPH, CBZ or sodium valproate (VAL) to determine the most effective method of monitoring thyroid status in an epilepsy clinic.

Correspondence: R.T. Jung M.D., F.R.C.P. (Ed), Wards 3/4, Department of Medicine, Ninewells Hospital, Dundee DD1 9SY, Scotland, UK.

Accepted: 16 April 1987

\section{Patients and methods}

Seventy-one consecutive patients receiving either DPH, CBZ or VAL were studied. The patients were attending a neurology outpatient clinic and had been taking a single anticonvulsant for at least 6 months with dosage stabilized for at least 3 months prior to entry. Patients whose seizures were not controlled, or who were receiving more than one anticonvulsant drug were excluded. At the patient's clinic attendance, the serum level of DPH, CBZ or VAL was measured. In addition, thyroid function was assessed by measuring serum total thyroxine $\left(\mathrm{T}_{4}\right)$ by polyethylene glycol precipitated in-house radioimmunoassay, TSH by double antibody in-house radioimmunoassay and free thyroxine $\left(\mathrm{FT}_{4}\right)$ by a commerical kit (Coat-a-Count kit, Diagnostic Products UK Ltd). The TSH assay has a lower limit of sensitivity of $0.5 \mathrm{mU} / 1$. To determine true thyroid status, patients with an abnormality of one or more of these thyroid tests were requested to attend for further investigation by a thyrotrophin releasing hormone (TRH) test, the serum TSH level being measured before, 20 and 60 minutes after an intravenous injection of $200 \mu \mathrm{g}$ TRH (Roche). Our reference range for $T_{4}$ is 75 to $145 \mathrm{nmol} / 1$, for $\mathrm{FT}_{4} 10.3$ to $18.9 \mathrm{pmol} / 1$ and for basal serum TSH is less than $4.6 \mathrm{mU} / 1$. We define a normal TRH test as showing a 20 minute rise to $20 \mathrm{mU} / 1$ or less in a male and to 
$24 \mathrm{mU} / \mathrm{l}$ or less in a female with a subsequent fall at 60 minutes. A Crooks-Wayne diagnostic index for hypothyroidism was also performed.

Statistical significance was determined by the Chisquared test for differences in distribution and the Student's $t$ test for differences between means.

Approval for this study was given by Tayside Health Board Ethical Committee.

\section{Results}

Details of the patients, their drug dosages and prevailing serum anticonvulsant levels are shown in Table $I$. Those treated with CBZ or DPH had a mean basal serum $\mathrm{T}_{4}$ and $\mathrm{FT}_{4}$ level which was significantly lower than those treated with VAL (Table II). Significantly more patients in the VAL group had a serum $\mathrm{T}_{4}$ and $\mathrm{FT}_{4}$ within the normal reference range; $85 \%$ of those on VAL had a normal $\mathrm{T}_{4}$ as compared with $40 \%$ on CBZ $(P<0.001)$ and $39 \%$ on DPH $(P<0.001)$. A normal $\mathrm{FT}_{4}$ was found more often than a normal $\mathrm{T}_{4}$; $95 \%$ of those on VAL had a normal $\mathrm{FT}_{4}$ compared with $70 \%$ on CZB $(P<0.01)$ and $65 \%$ on DPH $(P<0.01)$. All the patients with a low $\mathrm{FT}_{4}$ also had a low $T_{4}$. There was no significant difference in the distribution of normal TSH results between the 3 groups; $90 \%$ on VAL, $90 \%$ on $\mathrm{CBZ}$ and $94 \%$ on DPH.

In 36 patients at least one parameter was outside the reference range and on our criteria a TRH test was indicated; 27 were carried out (Table III). The reasons for not carrying out a TRH test in 9 of the patients in which it was indicated were as follows: two refused to attend, one had ceased therapy against medical advice and six had had an additional anticonvulsant drug added in the meantime to their therapy. A TRH test was indicated in these 9 patients because of a low $\mathrm{T}_{4}$ in all of them, because of a low $\mathrm{FT}_{4}$ in 2 and because of a basal TSH of $5.9 \mathrm{mU} / 1$ in one subject, although she had a normal $\mathrm{T}_{4}$ and $\mathrm{FT}_{4}$. In the 27 patients where a TRH was carried out, an hyperdynamic TSH response from a normal basal TSH level was found in two patients who each exhibited a low $\mathrm{T}_{4}$ and a low $\mathrm{FT}_{4}$ (Table III). Another patient had an elevated peak TSH of $27.2 \mathrm{mU} / 1$ after TRH and a basal value of $21.7 \mathrm{mU} / \mathrm{l}$; this patient was aged 85 years, had a low $T_{4}$ and a low $\mathrm{FT}_{4}$. In three further patients there were some unusual features to their TRH test but in each case $\mathrm{T}_{4}$ was low but $\mathrm{FT}_{4}$ normal. The response was borderline in one, hypothalamic in another and normal in the third despite an elevated basal value. In another the screening TSH was $7.0 \mathrm{mU} / 1$ but when the TRH test was carried out the basal TSH $(3.5 \mathrm{mU} / \mathrm{l})$ and response were normal; this patient had a low $\mathrm{T}_{4}$ but normal $\mathrm{FT}_{4}$. The Crooks-Wayne index of hypothyroidism would have diagnosed definite hypothyroidism in one patient and doubtful hypothyroidism in another (Table III).

As a prediction of a hyperdynamic TRH response, $\mathrm{FT}_{4}$ was $21 \%$, TSH $20 \%$ and $\mathrm{T}_{4} 11 \%$ accurate. The sensitivity of each test for a hyperdynamic TSH response to TRH was $100 \%$ for $\mathrm{FT}_{4}$ and $\mathrm{T}_{4}$ but only $33 \%$ for TSH.

\section{Discussion}

Both DPH and CBZ have been shown to decrease the serum levels of $\mathrm{T}_{4}$, free thyroxine index and $\mathrm{FT}_{4}{ }^{6-12} \mathrm{C}$ VAL has been less intensively investigated and foundo to decrease $T_{4}$ and $\mathrm{FT}_{4}$ though to a lesser degree and some have reported no consistent change. ${ }^{3,8,13}$ Our study shows that a normal $\mathrm{T}_{4}$ and $\mathrm{FT}_{4}$ are found in significantly more patients on VAL compared with CBZ or DPH.

Although all three anticonvulsants cause displacement of $T_{4}$ from thyroid binding globulin, ${ }^{14}$ this does not appear to be the major reason for the depression of serum thyroid hormone levels. For instance, it has been estimated that DPH given to man in therapeutic dosages is about ten times more effective in lowering the serum $\mathrm{T}_{4}$ than would be predicted from its in vitro potency for displacing $T_{4}$ from its serum binding sites. ${ }^{15}$ It is now thought that the major determinant in the case of CBZ and DPH is accelerated hormone clearance due to hepatic enzyme

Table 1 Details of patients studied

\begin{tabular}{lcccccc}
\hline & $n$ & Male (\%) & Age (years) & $\begin{array}{c}\text { Daily drug dose } \\
(\mathrm{mg})\end{array}$ & $\begin{array}{c}\text { Drug level } \\
(\mu \mathrm{mol} / \mathrm{l})\end{array}$ & $\begin{array}{c}\text { Usual therapeutic levels } \\
(\mu \mathrm{mol} / \mathrm{l})\end{array}$ \\
\hline Valproate & 20 & 50 & $\begin{array}{c}27 \pm 13 \\
(15-58)\end{array}$ & $\begin{array}{c}972 \pm 476 \\
(500-2500)\end{array}$ & $\begin{array}{c}388 \pm 206 \\
(190-800)\end{array}$ & $300-900$ \\
Carbamazepine & 20 & 50 & $\begin{array}{c}32 \pm 16 \\
(13-63)\end{array}$ & $\begin{array}{c}594 \pm 298 \\
(300-1400)\end{array}$ & $\begin{array}{l}(12-58) \\
304 \pm 95\end{array}$ & $\begin{array}{l}44 \pm 30 \\
(10-129)\end{array}$ \\
Phenytoin & 31 & 52 & $\begin{array}{l}40 \pm 20 \\
(16-85)\end{array}$ & & $(150-500)$ & $40-80$
\end{tabular}

\footnotetext{
${ }^{\dagger}$ Mean \pm 1 s.d. Range in parenthesis.
} 

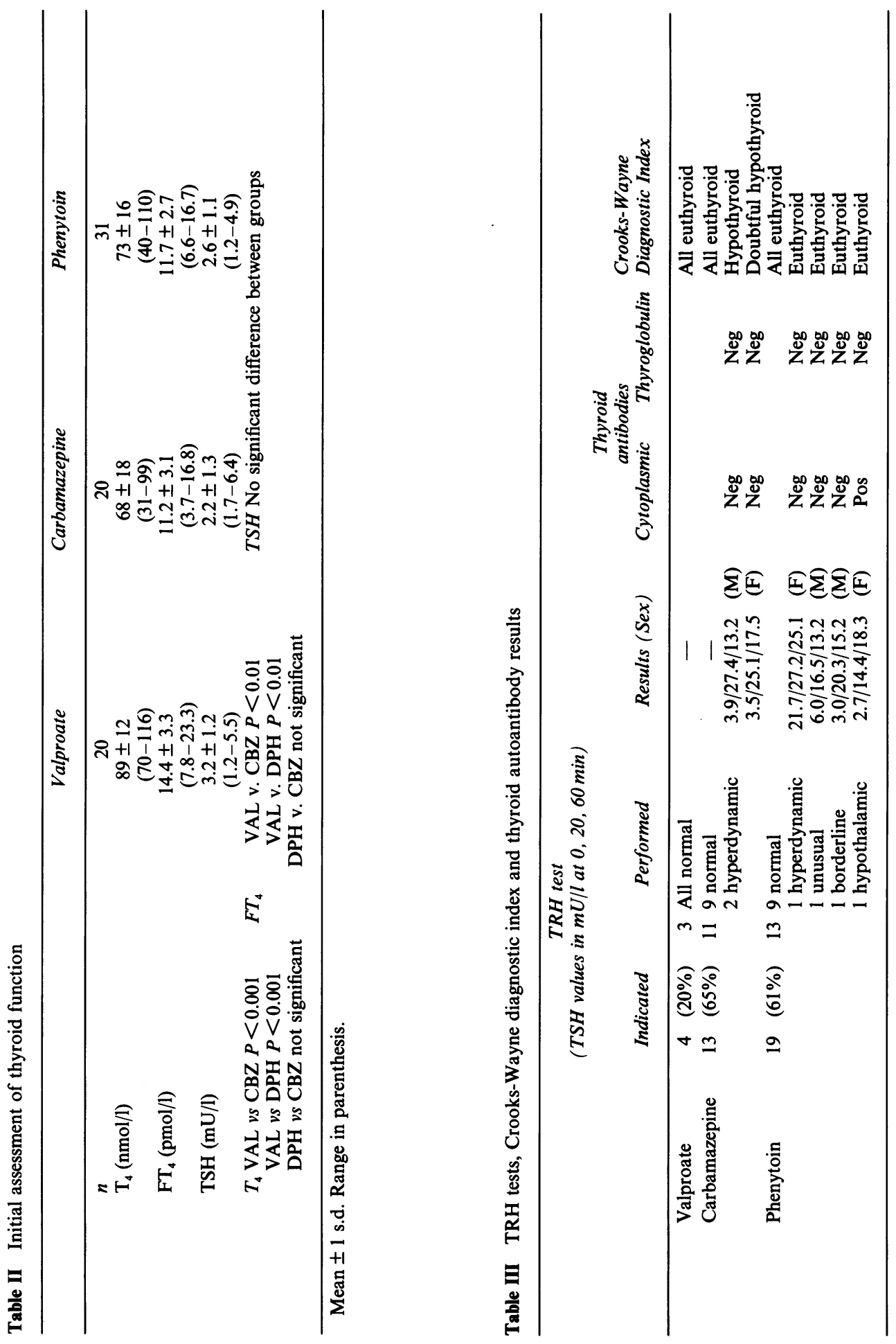
induction. ${ }^{2,10,15-17}$ Assessment of antipyrine clearance and urine D-glucarid acid excretion has indicated that CBZ and DPH induce hepatic microsomal enzymes in a marked and dose-dependent fashion whereas VAL has no significant effect. ${ }^{18}$ Therefore, unlike CBZ and DPH which are stereochemically related, ${ }^{19}$ VAL appears to have minimal hepatic enzyme induction properties and hence the mechanism by which it may lower $\mathrm{T}_{4}$ and $\mathrm{FT}_{4}$ is still uncertain.

In animal and tissue culture studies DPH may also affect hypothalamic TRH and pituitary TSH release ${ }^{20}$ and some human studies have shown a significant rise of basal serum TSH with CBZ or DPH therapy although in most cases TSH remains just within the normal reference range ${ }^{2,4}$ In the series of Fichsel and Knopfle, ${ }^{3} 4$ out of 50 children on diverse anticonvulsants had an exaggerated response to TRH, three of whom had a hypothalamic type of response.

In this study, if serum $\mathrm{T}_{4}$ alone had been used as a screening test of thyroid function then about $60 \%$ of those treated with DPH or CBZ and $15 \%$ of those on VAL would have had a subnormal value necessitating further thyroid investigation. The use of a clinical score such as the Crooks-Wayne index would only have diagnosed one patient as definitely hypothyroid and another as doubtful hypothyroid. The addition of basal serum TSH would have supported the possibility of hypothyroidism in just 4 patients, only one of whom was conclusively hypothyroid on a TRH test. An hyperdynamic TRH response was a feature in 2 other patients neither of whom had an abnormal basal

\section{References}

1. Ramsay, I. Drug and non-thyroid induced changes in thyroid function tests. Postgrad Med J 1985, 61: 375377.

2. Molholm Hansen, J., Skovsted, L., Lauridsen, U.B., Kirkegaard, C. \& Siersback-Nielsen, K. The effect of diphenylhydantoin on thyroid function. $J$ Clin Endocrinol Metab 1974, 39: 785-789.

3. Fichsel, H. \& Knopfle, G. Effects of anticonvulsant drugs on thyroid hormones in epileptic children. Epilepsia 1978, 19: 323-336.

4. Rousso, I., Pharmakiotis, A., Gatzola, M., Karatza, E. \& Sklavounou-Tsouroutsoglou, S. Effects of phenobarbital, diphenylhydantoin and carbamazepine on thyroid function in epileptic children. Acta Endocrinol 1984, 265 (suppl): 48-49.

5. Aanderud, S. \& Strandjord, R.E. Hypothyroidism induced by anti-epileptic therapy. Acta Neurol Scand 1980. 61: 330-332.

6. Liewendahl, K.\& Majuri, H. Thyroxine, triiodothyronine and thyrotropin in serum during long-term disphenylhydantoin therapy. Scand J Clin Lab Invest 1976, 36: $141-144$

7. Rootwelt, K., Ganes, T. \& Johannessen, S.I. Effect of carbamazepine, phenytoin and phenobarbitone on serum levels of thyroid hormones and thyrotropin in serum TSH level. Basal serum TSH was also normal in the patient with a hypothalamic TRH response and in the subjects with a borderline hyperdynamic TRH response. Hence the addition of basal serum TSH in the screening of anticonvulsant treated epileptics does not appear to provide much additional information.

Free $\mathrm{T}_{4}$ was abnormal in about one-third of those on CBZ and DPH and in 5\% of those treated with VAL. We found that in no single case was a reduction in $\mathrm{FT}_{4}$ associated with a normal $\mathrm{T}_{4}$. Neither of the 2 patients with a low $\mathrm{T}_{4}$ but normal $\mathrm{FT}_{4}$ required thyroid replacement therapy on biochemical or clinical grounds. Each of the 3 patients, who on clinical grounds and TRH evaluation would require thyroxine replacement, also had a subnormal $\mathrm{FT}_{4}$. Hence the use of serum $\mathrm{FT}_{4}$ would appear to be the most efficient screening test for hypothyroidism in this group of patients. The use of $\mathrm{FT}_{4}$ alone would have reduced the number of TRH tests by $60 \%$ representing not only a considerable financial saving, but also a saving of medical effort, patient inconvenience and a reduced risk of the rare but still significant danger of cardiac collapse following TRH.

\section{Acknowledgements}

This study was supported financially by a Tayside Healt Board Research Grant and by Labaz. We thank Miss G.M. Bernacca for her technical assistance. humans. Scand J Clin Lab Invest 1978, 38: 731-736.

8. Liewendahl, K., Majuri, H. \& Helenius, T. Thyroid function tests in patients on long-term treatment with various anticonvulsant drugs. Clin Endocrinol 1978, 8: 185-191.

9. Cavalieri, R.R., Gavin, L.A., Wallace, A., Hammond, M.E. \& Cruse, $K$. Serum thyroxine, free $T_{4}$, triiodothyronine and reverse- $\mathrm{T}_{3}$ in diphenylhydantoin-treated patients. Metabolism 1979, 28: 1161-1165.

10. Strandjord, R.E., Aanderud, S., Myking, O.L. \& Johannessen, S.I. Influence of carbamazepine on serum thyroxine and triiodothyronine in patients with epilepsy. Acta Neurol Scand 1981, 63: 111-121.

11. Yeo, P.P.B., Bates, D., Howe, J.G. et al. Anticonvulsants and thyroid function. $\mathrm{Br} \mathrm{Med} J$ 1978, 1: 1581-1583.

12. Franklyn, J.A., Sheppard, M.C. \& Ramsden, D.B. Measurement of free thyroid hormones in patients on long-term phenytoin therapy. Eur J Clin'Pharmacol 1984, 26: 633-634.

13. Bentsen, K.D., Gram, L. \& Veje, A. Serum thyroid hormones and blood folic acid during monotherapv with carbamazepine or valproate. Acta Neurol Scand 1983, 67: $235-241$.

14. Oppenheimer, J.H. \& Tavernetti, R.R. Studies on the thyroxine-diphenylhydantoin interaction: effect of 5,5'diphenylhydantoin on the displacement of $\mathrm{L}$-thyroxine 
from thyroxine-binding globulin. Endocrinology 1962, 71: 496-504.

15. Larsen, P.R., Atkinson, A.J., Wellmann, H.N. \& Goldsmith, R.E. The effect of diphenylhydantoin on thyroxine metabolism in man. J Clin Invest 1970, 49: 1266-1279.

16. Aanderud, S., Myking, O.L. \& Strandjord, R.E. The influence of carbamazepine on thyroid hormones and thyroxine binding globulin in hypothyroid patients substituted with thyroxine. Clin Endocrinol 1981, 15: 247252.

17. Connell, J.C.M., Rapeport, W.G., Gordon, S. \& Brodie, M.J. Changes in circulating thyroid hormones during short-term hepatic enzyme induction with car- bamazepine. Eur J Clin Pharmacol 1984, 26: 453-456.

18. Perucca, E., Hedges, A., Makki, K.A., Ruprah, M., Wilson, J.F. \& Richens, A. A comparative study of the relative enzyme inducing properties of anticonvulsant drugs in epileptic patients. Br J Clin Pharmacol 1984, 18: 401-410.

19. Rootwelt, K., Ganes, T. \& Johannessen, S.I. Effect of carbamazepine, phenytoin and phenobarbitone on serum levels of thyroid hormones and thyrotropin in humans. Scand J Clin Lab Invest 1978, 38: 731-736.

20. Smith, P.J. \& Sarks, M.I. Multiple effects of $5^{\prime} 5^{\prime}$-diphenylhydantoin on the thyroid hormone system. Endocrine Reviews 1984, 5: 514-524. 